\begin{tabular}{c} 
Original Articles \\
\hline Juntendo Medical Journal \\
2016. 62 (3), 232-239
\end{tabular}

\title{
Effects of Transdermal Nicotine Patches on Energy Expenditure Measured with a Human Calorimeter
}

\author{
TAKASHI NAKAGATA*1), HISASHI NAITO*1), SHIZUO KATAMOTO*1), \\ HIROYUKI KOBAYASHI*1) 2), SUSUMU S. SAWADA*1) 3) \\ *1) Graduate School of Health and Sports Science, Juntendo University, Chiba, Japan, *2) Mito Medical Center, Tsukuba \\ University Hospital, Ibaraki, Japan, *3) Department of Health Promotion and Exercise, National Institute of Biomedical \\ Innovation, Health and Nutrition, Tokyo, Japan
}

Objective: Previous studies investigating the link between nicotine and energy expenditure (EE) have shown a $6-10 \%$ increase in EE after nicotine intake using gum or spray, which increase blood level acutely. However, the effects of transdermal nicotine patches, which increase nicotine blood levels gradually, are still unknown. Thus, we studied the effects of nicotine patches on EE using human calorimeter.

Design: EE was measured over a 10-hour period with a human calorimeter using a crossover design to assess whether transdermal nicotine patches increase EE. Subjects were 8 adult, male non-smokers.

Interventions: All subjects followed the same schedule for measurement: enter the human calorimeter at 6:45 PM, sleep from 11:00 PM to 6:00 AM, and rest on a chair from 6:00 AM to 7:00 AM. EE and Respiratory quotient (RQ) were calculated from measurements from the human calorimeter.

Results: There were no significant differences in EE during the sleeping period between experimental and control conditions (Nicotine: $1.08 \pm 0.08 \mathrm{kcal} / \mathrm{min}$, Control: $1.06 \pm 0.08 \mathrm{kcal} / \mathrm{min} ; \mathrm{p}=0.161$ ). EE while sitting at rest $10 \mathrm{~h}$ after nicotine patch application was significantly increased by $0.07 \mathrm{kcal} / \mathrm{min}(5.8 \%)$ in the nicotine condition compared to the control condition (Nicotine: $1.22 \pm 0.10 \mathrm{kcal} / \mathrm{min}$, Control: $1.15 \pm 0.12 \mathrm{kcal} / \mathrm{min} ; \mathrm{p}=0.035$ ).

Conclusion: Results from this study indicate that EE may increase after transdermal nicotine patch exposure when blood nicotine levels have reached an estimated maximum.

Key words: resting energy expenditure, human calorimeter, nicotine replacement therapy

\section{Introduction}

Smoking is a major cause of cancer, cardiovascular diseases, diabetes, and many other diseases. Smoking is also the second leading risk factor for global all-cause mortality after hypertension ${ }^{1)}$. Therefore, prevention of passive smoking and providing smoking cessation programs are essential for improving public health. The World Health Organization has set a goal of reducing the global smoking rate by $30 \%$ by $2025^{2)}$. However, many smokers attempting to quit smoking experience nicotine withdrawal symptoms, such as cravings, anxiety, irritability, and depression, in the early stages of cessation. Many smokers relapse when attempting to quit because of these symptoms. In recent years, nicotine replacement therapy, in which nicotine is administered in the form of a patch or chewing gum to relieve withdrawal symptoms and urges, has been broadly used as an effective means to support smoking cessation efforts $^{3)}$.

\footnotetext{
Corresponding author: Takashi Nakagata

Graduate School of Health and Sports Science, Juntendo University

1-1 Hirakagakuendai, Inzai-shi, Chiba 270-1695, Japan

TEL: +81-476-98-1001 FAX: +81-476-98-1030 E-mail: takashi.nakagata@gmail.com

〔Received Dec. 9, 2015〕〔Accepted Mar. 10, 2016〕
}

Copyright (C) 2016 The Juntendo Medical Society. This is an open access article distributed under the terms of Creative Commons Attribution License (CC BY), which permits unrestricted use, distribution, and reproduction in any medium, provided the original source is properly credited. doi: $10.14789 /$ jmj. 62.232 
Cardiovascular risks are greatly reduced for those who succeed in smoking cessation ${ }^{4)}$; however, successful smoking cessation is often accompanied by weight gain $^{5-7)}$, which is also a known risk factor for cardiovascular disease. Aubin $e t$ al. ${ }^{8)}$ conducted a meta-analysis that showed participants experienced a $4-5 \mathrm{~kg}$ increase in body weight in the year following successful smoking cessation. Hofstetter et $a l^{9)}$ compared 24-hour energy expenditure (EE) in smokers with a human calorimeter and reported a $200 \mathrm{kcal}$ increase in $\mathrm{EE}$ on the day subjects smoked every 30 minutes compared to a day without smoking. Therefore, post-smoking cessation weight gain, which is also a public health issue, is considered to be a phenomenon related to the pharmacological effect of nicotine on EE.

Previous studies investigating the link between nicotine replacement therapy, in gum or spray form, and $\mathrm{EE}$ have shown a 6-10\% increase in $\mathrm{EE}$ immediately after nicotine intake ${ }^{10)-13)}$. However, some of these studies ${ }^{10-12)}$ were based on respiration mask measurements over the short term. In addition, the effects observed were measured after a short period of non-smoking, from several hours to overnight. Thus, possible effects on EE from nicotine withdrawal, such as smoking urges and other non-nicotine factors associated with temporary smoking cessation, cannot be ruled out. In the present study, we studied the effects of transdermal nicotine patches on EE measured over a 10-hour period with a human calorimeter in non-smokers who had no nicotine withdrawal symptoms or urges.

\section{Materials and methods}

\section{Subjects}

This study included 10 adult male non-smokers aged 23 to 28 years old. Prior to the study, all subjects provided written consent to participate after receiving information on risks and adverse effects associated with nicotine patch application. Although none of the subjects in this study encountered any adverse effects from the nicotine patches during pre-screening, 2 of the 10 subjects reported headaches, nausea, and other symptoms after waking following nicotine patch application in the main study, and were thus excluded from analysis. Total subject count for analysis was 8 . The study protocol was approved by the Research Ethics Review Board of the Juntendo University
Graduate School of Health and Sports Science (Tokyo, Japan).

\section{Study design}

We used a crossover experimental design; initial conditions were determined randomly for each subject. Subject EE was measured twice: once when a nicotine patch was applied to subjects (nicotine condition), and once with placebo patches (control condition). Both measurements were conducted within a period of 7-10 days, and all subjects completed calorimetry measurements between early August and mid-September of 2013.

\section{Energy expenditure measurements}

Energy expenditure was measured with a human calorimeter (FHC-20S, Fuji Medical Science) from 6:30 PM to 8:15 AM the next morning. A human calorimeter is a piece of equipment used to measure $\mathrm{EE}$ indirectly from oxygen uptake $\left(\mathrm{VO}_{2}\right)$ and carbon dioxide production $\left(\mathrm{VCO}_{2}\right)$ volumes in a hermetically-sealed room in which a subject can live normally for several hours to days. The human calorimeter used in this study had an internal volume of 19,000 L and facilities (e.g., bed, toilet, desk, chair, television and phone). Temperature and humidity of the internal atmosphere were adjusted to $25^{\circ} \mathrm{C}$ and $55 \%$, respectively. With an exhaust flow rate of $100 \mathrm{~L} / \mathrm{min}, \mathrm{O}_{2}$ and $\mathrm{CO}_{2}$ exhaust concentrations were measured every $15 \mathrm{~s}$ with a mass spectrometer and used to calculate $\mathrm{VO}_{2}$ and $\mathrm{VCO}_{2}$ per min based on Henning's formula ${ }^{14)}$. The $\mathrm{EE}$ was calculated by applying the resulting $\mathrm{VO}_{2}$ and $\mathrm{VCO}_{2}$ to Weir's formula ${ }^{15}$. The resulting EE values, adjusted for a $2-$ min time lag, were used for data analyses. Alcohol combustion tests (7-h combustion) indicated theoretical recoveries of $\mathrm{O}_{2}$, $\mathrm{CO}_{2}$, and respiratory quotient (RQ) of, respectively, $101.4 \%, 101.5 \%$ and $100.0 \%$ before the study and $99.4 \%, 100.5 \%$ and $101.1 \%$ after the study. These results guaranteed accurate calorimetry measurements. Prior to the study, all subjects stayed in the human calorimeter at least once with a schedule similar to the one used in the actual experiment to acclimatize to the living environment.

The experimental schedule set for all subjects is shown in Table-1. The subjects in this study refrained from any strenuous physical activity, including general exercise, from the day before 
Table-1 Time schedule in the human calorimeter

\begin{tabular}{lc}
\hline Time & Activity \\
\hline 6:30 PM & Enter the calorimeter \\
6:30 PM-7:00 PM & Sitting, reading, or watching TV \\
7:00 PM-7:15 PM & Dinner \\
7:15 PM-11:00 PM & Desk work or watching TV \\
9:00 PM & Nicotine patch application \\
11:00 PM & Sleep \\
6:00 AM & Wake up (go to the toilet) \\
6:00 AM-7:00 AM & Sitting (TV watching only) \\
7:00 AM-8:00 AM & Sitting, reading, or watching TV \\
8:15 AM & Exit the calorimeter \\
\hline
\end{tabular}

measurements began; fasted (but were allowed water) beginning at 3:00 $\mathrm{PM}$ on the day of measurement; and arrived at the laboratory to begin the experiment at 6:00 PM. The subjects then underwent height and weight measurements, wore electrodes for electrocardiography, and entered the human calorimeter at 6:30 PM. The subjects stayed in the human calorimeter for $13 \mathrm{~h}$ and 45 min, exiting at 8:15 AM the next morning.

Regarding activities in the human calorimeter, the subjects were instructed as follows:

1) From the time of entrance to 11:00 PM, subjects were not allowed to exercise or lie in bed, and passed time by sitting on a chair and watching television or working on a computer, except while using the toilet.

2) At 7:00 PM, subjects were given a meal provided by the examiner in the human calorimeter. The contents of the meal were identical for the nicotine and control conditions for each subject.

3) The subjects slept from 11:00 PM to 6:00 AM.

4) Upon waking at 6:00 AM, subjects sat on a chair immediately after defecation/urination and remained in a resting state while in a sitting posture for $1 \mathrm{~h}$ while watching television until 7:00 AM.

5) The subjects passed time by sitting on a chair and watching television or working on a computer from 7:00-8:15 AM, after which they exited the calorimeter.

Adherence to instructions was checked by visually inspecting the subjects on a regular basis and confirmed with the subjects in writing after exiting the calorimeter. Subjects' heart rates (beats per minute, bpm) were recorded throughout their entire stay in the human calorimeter with an electrocardiograph (DS-7520, Fukuda Denshi). Body fat percentage and skeletal muscle mass were estimated using the impedance method (Inbody 730, Biospace). $\mathrm{EE}$ and $\mathrm{RQ}$ were calculated from measurements in the human calorimeter.

\section{Nicotine patches}

In this study, nicotine patches were used to assess the pharmacological effects of nicotine from nicotine replacement therapy on EE. Since blood nicotine levels are estimated to peak 8-10 h after nicotine patch application ${ }^{16)}$, a nicotine patch (Nicotinell 20, $20 \mathrm{~cm}^{2}, 35 \mathrm{mg} / 24 \mathrm{~h}$ ) was applied to the left arm of each subject in the nicotine condition at 9:00 PM to obtain the highest blood nicotine level at 6:00 AM when the subject awoke. Meanwhile, a patch devoid of nicotine was applied to the left arm of each subject in the control condition at 9:00 PM. Because headaches and nausea can be caused by nicotine patch application and could affect study results, candidate subjects underwent pre-screening, wherein patches with a lower nicotine content were tested on the subjects for $10 \mathrm{~h}$ prior to the study; only those who did not experience adverse effects, such as headaches and nausea, were included.

\section{Statistical analyses}

Microsoft Office Excel 2008 and PASW Statistics 17.0 were used for data processing and statistical analyses, respectively. All variable results are presented as mean \pm standard deviation. All data obtained every hour from 9:00 PM to 7:00 AM were averaged. Statistical analyses were performed using a two-way analysis of variance (ANOVA) with repeated measures to evaluate the effect of the nicotine patch on $\mathrm{EE}$ (Condition $\times$ Time). Statistical significance level was set at 0.05 .

\section{Results}

Characteristics and body composition of included subjects are shown in Table-2. Mean age and body mass index were $26.3 \pm 1.7$ years and $22.2 \pm 1.6$ $\mathrm{kg} / \mathrm{m}^{2}$, respectively.

Table- 3 and Figure -1 show changes in EE while the subjects were in the human calorimeter. There was a significant main effect of time but no 
Table-2 Subjects' characteristics $(n=8)$

\begin{tabular}{lccccccc}
\hline Variables & Age $(\mathrm{y})$ & Height $(\mathrm{cm})$ & Weight $(\mathrm{kg})$ & BMI $\left(\mathrm{kg} / \mathrm{m}^{2}\right)$ & Muscle mass $(\mathrm{kg})$ & Body fat mass $(\mathrm{kg})$ & $\%$ Body fat $(\%)$ \\
\hline Mean & 26.3 & 173.0 & 66.6 & 22.6 & 31.7 & 10.5 & 15.8 \\
$\mathrm{SD}$ & 1.7 & 5.7 & 6.8 & 1.6 & 3.4 & 1.9 & 1.8 \\
\hline
\end{tabular}

Table-3 Energy expenditure during stay in the human calorimeter $(\mathrm{n}=8)$

\begin{tabular}{lccc}
\hline Time & Nicotine $(\mathrm{kcal} / \mathrm{min})$ & Control $(\mathrm{kcal} / \mathrm{min})$ & $\mathrm{p}$ value \\
\hline Awake & $1.41 \pm 0.11$ & $1.41 \pm 0.13$ & 0.888 \\
9:00 PM-11:00 PM & $1.08 \pm 0.08$ & $1.06 \pm 0.08$ & 0.161 \\
$\begin{array}{l}\text { Sleeping } \\
\text { 11:00 PM-6:00 AM } \\
\text { Sitting }\end{array}$ & $1.22 \pm 0.10$ & $1.15 \pm 0.12$ & 0.035 \\
6:00 AM-7:00 AM & $1.16 \pm 0.03$ & $1.14 \pm 0.09$ & 0.262 \\
\hline $\begin{array}{l}\text { Overall } \\
\text { 9:00 PM-7:00 AM }\end{array}$ & & & \\
\hline
\end{tabular}

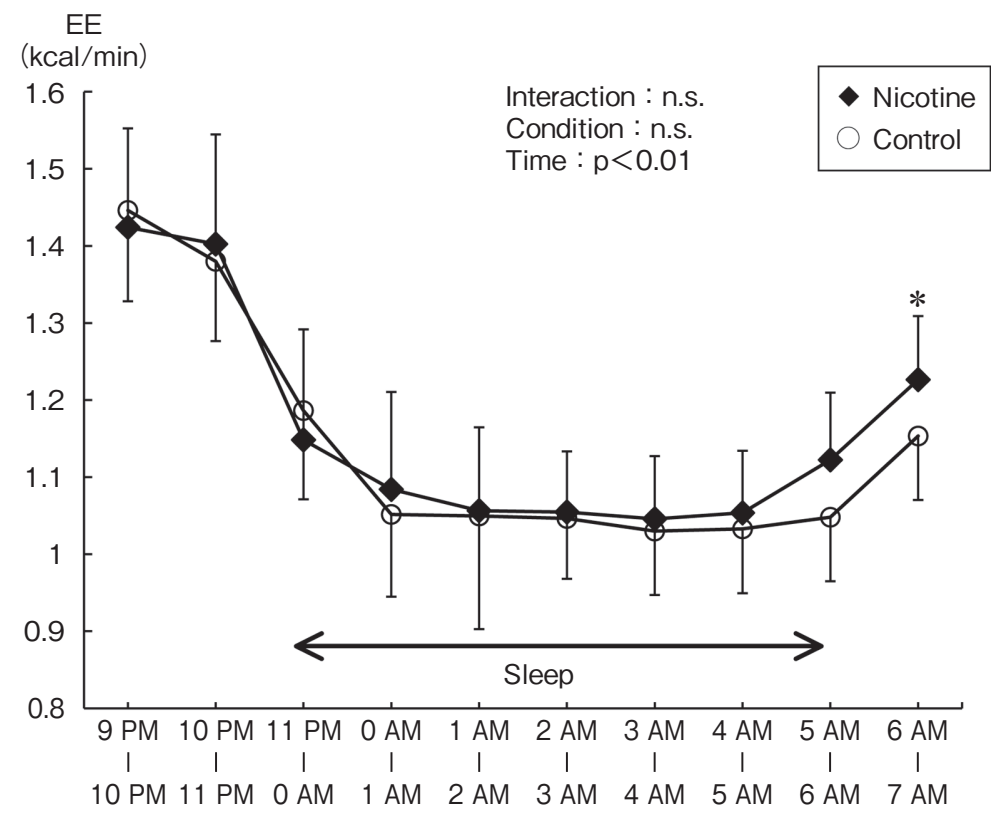

Figure-1 Mean hourly energy expenditure (EE) in the human calorimeter for nicotine and control $(\bigcirc)$ conditions. Significant differences $(*)$ was observed at 6:00-7:00 AM when subjects were sitting $(\mathrm{p}=0.035)$.

significant main effect of condition and interactions in EE. Total EE during sleeping period from 9:00 $\mathrm{PM}$ to 6:00 AM the next morning in the nicotine condition was $1.08 \pm 0.08 \mathrm{kcal} / \mathrm{min}$, which was not significantly different from the control condition total of $1.06 \pm 0.08 \mathrm{kcal} / \mathrm{min}(\mathrm{p}=0.161)$. The mean $\mathrm{EE}$ in the nicotine condition was significantly greater than the control condition only when subjects were sitting at rest (6:00-7:00 AM) (nicotine, $1.22 \pm 0.10 \mathrm{kcal} / \mathrm{min}$, control, $1.15 \pm 0.12$ $\mathrm{kcal} / \mathrm{min} ; \mathrm{p}=0.035$, Figure -1 ). At this time, blood nicotine levels had presumably reached their peak. The mean heart rate during the nicotine condition tended to be higher than during the control condition while subjects were sleeping (11:00 PM to 6:00 $\mathrm{AM}$ the next morning) (nicotine: $52.3 \pm$ $7.1 \mathrm{bpm}$, control: $49.9 \pm 6.3 \mathrm{bpm}$; $\mathrm{p}=0.068$, Table -4 ). During the resting hour after waking $(6: 00-7: 00$ $\mathrm{AM})$, the mean heart rate was significantly higher in the nicotine condition than that in the control condition (nicotine: $63.7 \pm 8.2 \mathrm{bpm}$, control: $56.9 \pm$ 7.3 bpm; p =0.011, Figure-2). 
Table-4 Heart rate during stay in the human calorimeter $(\mathrm{n}=8)$

\begin{tabular}{lccc}
\hline Time & Nicotine $(\mathrm{bpm})$ & Control $(\mathrm{bpm})$ & $\mathrm{p}$ value \\
\hline $\begin{array}{l}\text { Awaking } \\
\text { 9:00 PM-11:00 PM }\end{array}$ & $60.6 \pm 6.4$ & $60.7 \pm 7.0$ & 0.888 \\
$\begin{array}{l}\text { Sleeping } \\
\text { 11:00 PM-6:00 AM }\end{array}$ & $52.3 \pm 7.1$ & $49.9 \pm 6.3$ & 0.068 \\
$\begin{array}{l}\text { Sitting } \\
\text { 6:00 AM-7:00 AM }\end{array}$ & $63.7 \pm 8.2$ & $56.9 \pm 7.3$ & 0.011 \\
\hline $\begin{array}{l}\text { Total } \\
\text { ::00 PM-7:00 AM }\end{array}$ & $55.0 \pm 6.5$ & $52.7 \pm 5.9$ & 0.068 \\
\hline
\end{tabular}

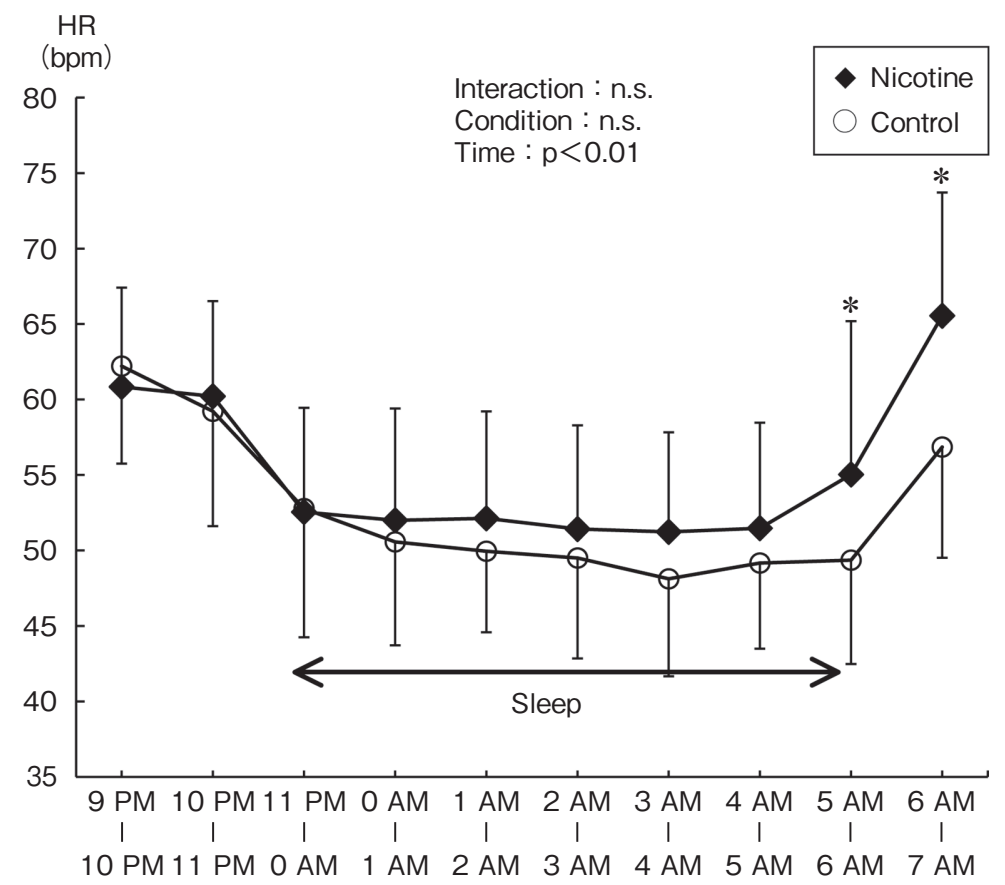

Figure-2 Mean hourly heart rate in the human calorimeter for nicotine $(\checkmark)$ and control $(\bigcirc)$ conditions. Significant differences $(*)$ was observed at 5:00-6:00 AM when subjects were sleeping $(\mathrm{p}=$ $0.017)$ and 6:00-7:00 AM when subjects were sitting $(\mathrm{p}=0.011)$.

The mean $\mathrm{RQ}$ in the nicotine condition was higher than in the control condition during sleeping (11:00 PM to 6:00 AM the next morning) (nicotine: $0.88 \pm 0.03$, control: $0.85 \pm 0.01 ; \mathrm{p}=0.035)$ and sitting at rest $(6: 00-7: 00 \mathrm{AM}$ ) (nicotine, $0.91 \pm 0.05$, control, $0.87 \pm 0.02 ; \mathrm{p}=0.035$, Table -5 , Figure-3). And, total RQ from 9:00 PM to 7:00 AM the next morning in the nicotine condition was significantly higer (nicotine, $0.89 \pm 0.03$, control, $0.86 \pm 0.02 ; \mathrm{p}=0.035)$.

\section{Discussion}

In this study, we investigated the effects of nicotine patch use on EE in non-smokers using a randomized crossover experimental design to assess whether transdermal nicotine patches increase EE measured over a 10-hour period with a human calorimeter. A distinguishing feature of this study is that although there were no significant differences in EE during sleep between the nicotine patch condition and the non-nicotine patch (control) condition, EE while sitting at rest $10 \mathrm{~h}$ after nicotine patch application was significantly increased by $0.07 \mathrm{kcal} / \mathrm{min}(5.8 \%)$ in the nicotine condition compared to the control condition.

Since Dill $e t a l{ }^{17)}$ and Hiestand $e t a l .{ }^{18)}$ reported increased $\mathrm{EE}$ in a resting state immediately after consuming a single cigarette, a number of studies have demonstrated that EE increases after various manners of nicotine intake, including smoking ${ }^{9-13)}$. 
Table-5 Respiratory quotient during staying human calorimeter $(\mathrm{n}=8)$

\begin{tabular}{lccc}
\hline Time & Nicotine & Control & p value \\
\hline $\begin{array}{l}\text { Awaking } \\
\text { 9:00 PM-11:00 PM }\end{array}$ & $0.90 \pm 0.03$ & $0.91 \pm 0.03$ & 0.779 \\
$\begin{array}{l}\text { Sleeping } \\
\text { 11:00 PM-6:00 AM }\end{array}$ & $0.88 \pm 0.03$ & $0.85 \pm 0.01$ & 0.035 \\
$\begin{array}{l}\text { Sitting } \\
\text { 6:00 AM-7:00 AM }\end{array}$ & $0.91 \pm 0.05$ & $0.87 \pm 0.02$ & 0.035 \\
\hline $\begin{array}{l}\text { Total } \\
\text { ::00 PM-7:00 AM }\end{array}$ & $0.89 \pm 0.03$ & $0.86 \pm 0.02$ & 0.035 \\
\hline
\end{tabular}

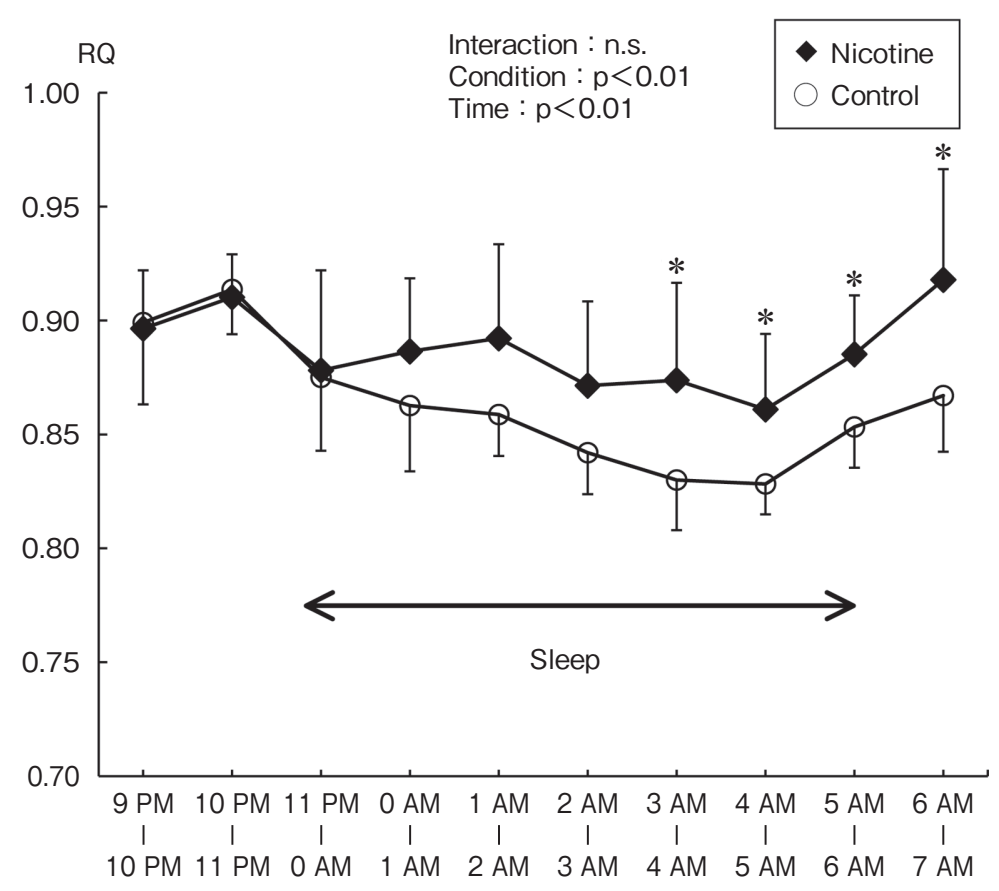

Figure-3 Mean hourly respiratory quotient $(\mathrm{RQ})$ in the human calorimeter for nicotine $(-)$ and control $(\bigcirc)$ conditions. * Significant difference was observed at 3:00-4:00 AM, 4:00-5:00 AM, and 5:00-6:00 AM when subjects were sleeping and 6:00-7:00 AM when subjects were sitting $(\mathrm{p}<0.05)$.

Hofstetter et al. ${ }^{9)}$ measured total EE over $24 \mathrm{~h}$ using a human calorimeter for subjects; when comparing the experimental condition of smoking (24 cigarettes per day) to the control condition (no smoking), 24-hour EE for the smoking condition was greater than that for the control $(+9.6 \%)$, with an approximate difference of $200 \mathrm{kcal}$ (smoking: $2,445 \pm 120$ kcal, control: $2,230 \pm 115 \mathrm{kcal} ; \mathrm{p}<0.001)$. The nicotine-induced increase in EE was attributable to the pharmacological effects of nicotine, including stimulation of the sympathetic and parasympathetic nervous systems and secretion of catecholamines (adrenaline and noradrenaline) ${ }^{19)}{ }^{20)}$. Although nicotine concentration in the blood was not measured in the current study, it has been reported that blood nicotine concentrations reach a maximum level $10 \mathrm{~h}$ after application of a nicotine patch similar to the one used in our study ${ }^{16)}$. While EE was not significantly different for the nicotine and control conditions in the observed period between 9:00 PM to 6:00 AM, EE was significantly increased by $0.07 \mathrm{kcal} / \mathrm{min}(5.8 \%)$ for the nicotine condition at rest $10 \mathrm{~h}$ after nicotine patch application. This confirmed that EE increased when blood nicotine levels were estimated to be sufficiently high (Table-3). In addition, a previous study showed that nicotine patches induce a $6-10 \mathrm{bpm}$ heart rate increase that occurs at least $7 \mathrm{~h}$ after application ${ }^{21)}$. In our study, the mean heart rate while sitting at rest $10 \mathrm{~h}$ after nicotine patch 
application was significantly increased by $6.9 \mathrm{bpm}$ in the nicotine condition compared to the control condition (Table-4). These results suggest that elevated nicotine concentrations in the blood and associated increases in heart rate may underlie the increased $\mathrm{EE}$ during the observed sitting period.

Our results showed an increase in $\mathrm{RQ}$ with transdermal nicotine patch application which means increased in the amount of carbohydrate oxidized. The increase in $\mathrm{RQ}$ with transdermal nicotine patch application might be explained by effects of nicotine, including stimulation of the sympathetic and parasympathetic nervous systems and secretion of catecholamines (adrenaline and noradrenaline ${ }^{19)}{ }^{20}$. Interestingly, in our study, the mean heart rate in nicotine condition was higher than control condition. Hofstetter et al. ${ }^{9)}$ reported that RQ during sleeping after smoking 24 cigarettes per day was elevated slightly and attributed this change to an increase in heart rate. Our results that an increase HR with transdermal nicotine patch application is consistent with their results. However, there is still scientific disagreement on the effects of nicotine on RQ. Perkins et al. ${ }^{10)}$ reported that RQ decreased with nicotine spray, but Jessen $e t$ $a l^{12)}$ found no significant change in RQ with nicotine gum. Concerning the effects of nicotine on $R Q$, further research is needed.

This study also has some limitations. First, we could not address possible differences in response to nicotine among the study subjects. Considering that two subjects had symptoms such as nausea when they awoke, it is plausible that nicotine responsiveness varied substantially from one individual to another. In a previous study reporting nicotine-induced increases in $\mathrm{EE}$, some subjects showed unchanged or decreased EE after nicotine application ${ }^{22)}$. And, unlike previous studies, our study was conducted with non-smokers; this allowed us to evaluate the effects of a transdermal nicotine patch on $\mathrm{EE}$ without any interference from nicotine withdrawal symptoms, smoking urges, and/or other non-nicotine factors associated with smokers who temporarily stop smoking. Therefore, it is unclear our findings may apply to current smokers. Future studies should be designed to consider the potential variation in nicotine responsiveness between individuals and be recruit smokers. Second, the study subjects exited the human calorimeter at 8:15 AM the following day, and changes in $\mathrm{EE}$ after that time were not investigated. Since most daily physical activities are non-exercise activity thermogenesis (NEAT) activities ${ }^{23}$, such as maintaining posture (sitting or standing) and fidgeting, the nicotine patch-induced increase in EE might have been masked by those activities. Further studies are necessary to determine the effects of nicotine replacement therapy on the total amount of daily $\mathrm{EE}$, including diet and physical activity. Third, transdermal nicotine patches were applied to each subject in the nicotine condition at 9:00 PM to obtain the highest blood nicotine level at next morning, yet nicotine patch users in nonexperimental conditions tend to apply a new patch in the morning. Although it has been suggested that use of the patch overnight could induce sleep disturbances, such as unpleasant or strange dreams ${ }^{24)}$, we did not measure adverse effects on sleep or polysomnographic measures of sleep quality. Thus, future studies should investigate EE during the morning combined with assessing adverse effects of overnight transdermal nicotine patch use. Finally, the fact that all study subjects were male represents another limitation given the possible differences in nicotine responsiveness between males and females. Lower smoking cessation success rates and greater increases in body weight have been reported for women undergoing nicotine replacement therapy compared with males undergoing the same treatment ${ }^{25)}$. These gender differences warrant further studies on the effects of nicotine replacement therapy on $\mathrm{EE}$ in a population including both men and women.

Our results that EE with nicotine patches increased by $5.8 \% 10 \mathrm{~h}$ post-application is important in clinical setting. Assuming that a nicotine patch is continuously applied and supplies nicotine sufficient to maintain the highest possible blood level for $12 \mathrm{~h}$, the expected increase in EE is 50-60 kcal, higher-dose transdermal nicotine patch may increase $\mathrm{EE}$ more. However, nicotine replacement therapy is used to gradually decrease the nicotine concentration (content) over time to achieve successful smoking cessation, the EE increase from the pharmacological effects of nicotine may be decreased as nicotine replacement therapy advances. Therefore, programs and information for prevention of weight gain, such as avoiding overeating 
and increasing physical activity will be suggested, even when smoking cessation is attempted with the aid of nicotine replacement therapy.

In conclusion, our study provides novel information on the effects of transdermal nicotine patches on increasing EE when blood nicotine levels have reached an estimated maximum and indicates that they may have null effects for preventing weight gain during smoking cessation.

Acknowledgments: We wish to thank all of the participants in our study.

\section{Ethical approval}

The Research Ethics Review Board of the Juntendo University Graduate School of Health and Sports Science (Tokyo, Japan) approved this study.

\section{Funding}

This work was supported in part by a collaborative research grant from the Juntendo University Graduate School of Health and Sports Science and Institute of Health and Sports Science \& Medicine.

\section{Conflict of interests}

None of the authors have any competing interests to disclose.

\section{References}

1) World Health Organization. Global health risks: mortality and burden of disease attributable to selected major risks. Geneva; 2009. Available at: http://www.who.int/ healthinfo/global_burden_disease/GlobalHealthRisks_ report_full.pdf. (accessed 7th December 2015)

2) World Health Organization. WHO framework convention on tobacco control: Outcomes of the sixth session of the conference of the parties. Moscow; 2014. Available at: http://www.who.int/fctc/cop/sessions/COP6_report_ FINAL_04122014.pdf. (accessed 7th December 2015)

3) Stead LF, Perera R, Bullen C, et al: Nicotine replacement therapy for smoking cessations. Cochrane Database Syst Rev, 2012; 11: CD000146.

4) Clair C, Rigotti NA, Porneala B, et al: Association of smoking cessation and weight change with cardiovascular disease among adults with and without diabetes. JAMA, 2013; 309: 1014-2021.

5) Lincoln JE: Weight gain after cessation of smoking. JAMA, 1969; 210: 1765.

6) Klesges RC, Meyers AW, Klesges LM, La Vasque ME: Smoking, body weight, and their effects on smoking behavior: a comprehensive review of the literature. Psychol Bull, 1989; 106: 204-230.

7) Perkins KA: Weight gain following smoking cessation. J Consult Clin Psychol, 1993; 61: 768-777.
8) Aubin HJ, Farley A, Lycett D, Lahmek P, Aveyard P: Weight gain in smokers after quitting cigarettes: meta-analysis. BMJ, 2012; 10: 345: e4439.

9) Hofstetter A, Schutz Y, Jéquier E, Wahren J: Increased 24-hour energy expenditure in cigarette smokers. N Engl J Med, 1986; 314: 79-82.

10) Perkins KA, Epstein LH, Stiller RL, Marks BL, Jacob RG: Acute effects of nicotine on resting metabolic rate in cigarette smokers. Am J Clin Nutr, 1989; 50: 545-550.

11) Klesges RC, DePue K, Audrain J, Klesges LM, Meyers AW: Metabolic effects of nicotine gum and cigarette smoking: Potential implications for postcessation weight gain? J Consult Clin Psychol, 1991; 59: 749-752.

12) Jessen AB, Toubro S, Astrup A: Effect of chewing gum containing nicotine and caffeine on energy expenditure and substrate utilization in men. Am J Clin Nutr, 2003; 77: $1442-1447$.

13) Compher C, Frankenfield D, Keim N, Roth-Yousey L; Evidence Analysis Working Group: Best practice methods to apply to measurement of resting metabolic rate in adults: a systematic review. J Am Diet Assoc, 2006; 106 : 881-903.

14) Henning B, Löfgren R, Sjöström L: Chamber for indirect calorimetry with improved transient response. Med Biol Eng Comput, 1996; 34: 207-212.

15) Weir JB: New methods for calculating metabolic rate with special reference to protein metabolism. J Physiol, 1949; 109: 1-9.

16) Urae A, Irie $S$, Amamoto $T$, Yoshiie $H$ : The tolerability, pharmacodynamics and pharmacokinetics of Ba37142 (Nicotine TTS) in a singly applied to investigate. Journal of Clinical Therapeutics and Medicines, 1994; 10: 3-34.

17) Dill DB, Edwards HT, Forbes WH: Tobacco smoking in relation to blood sugar, blood lactic acid and metabolism. Am J Physiol, 1934; 109: 118-122.

18) Hiestand WA, Ramsey HJ, Hale DM: The effects of cigarette smoking on metabolic rate, heart rate, oxygen pulse, and breathing rate. J Lab Clin Med, 1940; 25: 1013-1017.

19) Cryer PE, Haymond MW, Santiago JV, Shah SD: Norepinephrine and epinephrinerelease and adrenergic mediation of smoking-associated hemodynamic andmetabolic events. N Engl J Med, 1976; 295: 573-577.

20) Dietz R, Schömig A, Kusterer K, Dart AM, Kübler W: Vasopressor systems during smoking in humans. Klin Wochenschr, 1984; 62: 11-17.

21) Müller P, Imhof PR, Mauli D, Milovanovic D: Human pharmacological investigateons of a transdermal nicotine system. Methods Find Exp Clin Pharmacol, 1989; 11: 197-204.

22) Perkins KA, Sexton JE: Influence of aerobic fitness, activity level, and smoking history on the acute thermic effect of nicotine. Physiol Behav, 1995; 57: 1097-1102.

23) Westerterp KR: Assessment of physical activity: a critical appraisal. Eur J Appl Physiol, 2009; 105: 823-828.

24) Jain R, Majumder P, Gupta T: Pharmacological intervention of nicotine dependence. Biomed Res Int, 2013; 2013: 278392.

25) Perkins KA: Smoking cessation in women. Special considerations. CNS Drugs, 2001; 15: 391-411. 